\title{
ANÁLISE DE CRESCIMENTO E COMPORTAMENTO DE ALUNOS NA UTILIZAÇÃO DE PLAYERS DE VÍDEOS DE UMA STARTUP DE EDUCAÇÃO
}

\author{
ITAPERUNA/RJ MAIO/2018
}

\author{
Luiz Gustavo Xavier Borges - UNIREDENTOR - luizgustavo@redentor.edu.br \\ Andre Raeli Gomes - UNIREDENTOR - raeli@redentor.edu.br \\ Renato Marcelo Resgala Júnior - UNIREDENTOR - renatoresgalajr@gmail.com \\ Ludmilla Carvalho Rangel Resgala - UNIREDENTOR - ludmillacrangel@gmail.com
}

\author{
Tipo: Relato de Experiência Inovadora (EI) \\ Categoria: Métodos e Tecnologias \\ Setor Educacional: EDUCAÇÃO SUPERIOR
}

\begin{abstract}
RESUMO
O ensino superior no Brasil tem crescido ao longo dos últimos anos devido à uma série de políticas públicas que favoreceram a entrada do aluno nas instituições públicas e privadas. O perfil do aluno atual apresenta uma convergência com o avanço da tecnologia mundial e o setor de educação é amplamente impactado pela tecnologia da informação. A geração $Y$ ou Millennials, como são chamados os nascidos em meados dos anos 90 , tem como característica estarem sempre conectados, seja no notebook, smartphone ou computador, buscando informações de forma ágil e fácil, consumindo grande parte do seu tempo em redes sociais e canais de vídeos. O objetivo desta pesquisa foi analisar o crescimento de um canal de vídeo utilizando um player gratuito de oferta de conteúdos (YouTube) criado por uma startup do setor de educação, estruturado para auxiliar universitários a reforçar seus conhecimentos curriculares e medir, através de indicadores de acompanhamento para métricas de resultados, o comportamento desses usuários com relação à percepção do uso dos vídeos. Com essa pesquisa, pode-se afirmar que a busca por novas ferramentas de estudo foi evidenciada através de métricas baseadas no número de inscritos no canal, número de visualizações, perfil do aluno e também as métricas comportamentais, como ações "Gostei" e compartilhamentos nas redes sociais. $O$ resultado foi um crescimento progressivo do canal observado em questão.
\end{abstract}

Palavras-chave: vídeo-aulas; reforço acadêmico; tecnologia; educação

\section{AGRADECIMENTOS}

AGRADECEMOS À EMPRESA OBJETO DE ESTUdO QUE NÃO MEDIU ESFORÇOS EM AJUDAR NA DISPONIBILIDADE DOS DADOS PARA O SUCESSO DESTA PESQUISA. 


\section{INTRODUÇÃO}

O papel da educação, sua influência sobre a realização profissional e a mobilidade social têm sido um tema atrativo para as mais diversas pesquisas acadêmicas. Além disso, a educação tem se mostrado um importante contribuinte para o sucesso ao longo da vida, fazendo com que um dos temas abordados de forma recorrente para justificar essa relação é o aprofundamento dos estudos para o segmento do ensino superior (SMITH, 2014). Segundo Vieira (2015), o advento das Tecnologias de Informação e Comunicação (TIC) tem influenciado profundamente os rumos da educação em todo o mundo. Presenciamos uma nova realidade educacional em que as distâncias são minimizadas por meio da educação a distância, que vem crescendo significativamente.

Assim como diversas áreas, o setor de educação é impactado diretamente pelo avanço da tecnologia da informação ( $\mathrm{TI}$ ) e pela consolidação dos novos perfis e costumes de indivíduos que são atores neste processo. Segundo o Censo da Educação Superior no Brasil (INEP 2014), a média de idade dos alunos matriculados em 2012 é de 25 anos na modalidade presencial, com a moda em 21 anos. No caso da educação a distância, essas . No caso da educação à distância, essas estatísticas são 33 anos a média e 31 anos o valor modal.

A atual situação problema consiste na apresentação de uma ruptura dos modelos tradicionais de ensino praticados no ensino superior para a utilização de ferramentas tecnológicas de apoio ao aprendizado como um fator adicional. As questões de pesquisa são: qual é a intensidade da procura por novas ferramentas, o perfil de seus usuários e como ela se propaga através da internet em um mesmo canal?

O objetivo desta pesquisa é analisar o crescimento da utilização de um canal de apoio ao ensino universitário estruturado para atender o perfil da geração $\mathrm{Y}$, via player de vídeos abertos e gratuitos (YouTube) criado por uma startup do setor de educação, utilizando-se de indicadores de acompanhamento para métricas de resultados e perfil do comportamento de utilização do usuário.

\section{REFERENCIAL TEÓRICO}

2.1 - O Ensino Superior no Brasil e o Perfil do Universitário

O Censo da Educação Superior no Brasil (INEP 2014) registrou 7.305.977 de universitários matriculados no ensino superior no país, apresentando crescimento no período de 2012 a 2013 de 3,9\% nos cursos presenciais e 3,6\% nos cursos à distância, 
que já representam mais de $15 \%$ das matrículas de graduação. O Censo aponta, também, que mais de $63 \%$ dos alunos presenciais de graduação estudam à noite e que as Instituições de Ensino Superior (IES) privadas possuem mais de $74 \%$ no total de matrículas da graduação. A ampliação do ensino superior no Brasil deve-se à crescente demanda gerada na última década alinhada uma série de políticas públicas que possibilitaram o crescimento das vagas no ensino superior público e o acesso as IES privadas através de bolsas de estudos e financiamento estudantil. A implementação dessas políticas públicas permitiu o acesso ao ensino superior a jovens de classes menos favorecidas, provenientes de escolas públicas. (HERINGER, 2011)

Atualmente, a educação superior tem apresentado uma diferença no perfil universitário. Segundo Sobrosa et. al. (2014), os universitários que pertencem a uma classe socioeconômica inferior normalmente não conseguem obter um desempenho acadêmico satisfatório justamente por tentar conciliar trabalho com jornadas de estudos. Entretanto, encontram-se universitários com perfil oposto, que possuem dedicação exclusiva aos estudos e tendem a atingir um melhor desempenho acadêmico. Apesar dessa comparação, ambos universitários sofrem com alguns desafios ao ingressar em uma instituição de ensino superior. Magalhães (2013) afirma que entre esses desafios devemos mencionar o relacionamento social e temas acadêmicos, devido às diferenças de conhecimentos prévios de disciplinas de suporte ao ensino nas universidades.

\section{2 -A geração $Y$}

Segundo Alves (2011), as gerações da EaD perpassam pela comunicação através de cartas, transmissão de rádio, aulas na TV e a utilização da internet. Não há um consenso geral sobre definições e denominações, principalmente com relação à última geração. Smith (2014) considera os 18-30 anos de idade como os chamados Millennials.

É inevitável pensar a influência das ferramentas tecnológicas sobre os modelos de ensino aprendizagem utilizados na educação superior. Segundo Kotler e Keller (2006), os jovens da geração $Y$ são multitarefa. Eles conseguem, de forma simultânea, conversar com amigos ao telefone, visitar sites de relacionamentos, disparar mensagens e ouvir músicas. Pode-se afirmar que, assim como as bibliotecas estavam para gerações anteriores, a internet está para a geração Y. No entanto, existe uma negação na necessidade de se aprender ou se aprofundar em algo. Ao necessitar de uma informação, o jovem vai a um site de busca para realizar sua pesquisa. Mesmo com esse comportamento, a geração $Y$ ainda utiliza livros e materiais didáticos, não os abandonando como era temido. 
A geração $Y$ é parte de um ambiente digital e interativo, onde as mudanças nos meios de comunicação não assustam essa geração, que é considerada mais bem informada em relação aos seus antecessores. Os integrantes da geração $Y$ apresentam características que são facilmente identificadas, pois são inovadores, imediatistas, apresentam sempre uma conexão permanente com algum tipo de mídia e adoram mobilidade (VASCONCELOS et al., 2010).

\section{3 - A Tecnologia da Informação e Vídeos Online}

A tecnologia tornou-se uma ferramenta fundamental no processo de ensinoaprendizagem, trazendo recursos diferentes para uma educação dinâmica e renovada. O avanço tecnológico promoveu de forma mais rápida e simples o acesso à informação, oferecendo aos professores e alunos uma possibilidade infinita de obter e compartilhar informações (MAINARDI et al., 2014).

Os vídeos online têm se tornado cada vez mais populares, via sites como YouTube e Google Vídeos, com crescimento exponencial em seu número de usuários. Esse novo espaço de comunicação pode contribuir nas atividades educacionais, devendo ser encarado não somente como uma ferramenta de suporte as aulas, mas também como meio de comunicação. Portanto, esse espaço de comunicação consegue fazer parte de uma estratégia de ensino e aprendizado (LISBÔA et al., 2009).

Destaca-se que a busca por vídeos online pelos estudantes é crescente, os vídeos ajudam no processo de ensino-aprendizagem atendendo às necessidades dos alunos. Os vídeos devem ser desenvolvidos, principalmente, com a utilização de todos os recursos da linguagem audiovisual, visto que o usuário pode buscar uma informação clara, objetiva e didática. Os vídeos são validados pelo número de visualizações que apresenta, além de informar para os futuros usuários um grau de eficácia (SCHNEIDER et al., 2012). As tecnologias digitais emergentes possibilitam uma maior flexibilidade, liberdade e mobilidade nos programas educacionais. Desse modo, inclusice projetos pedagógicos passam a conciliar, na organização curricular, espaços, tempos e projetos que equilibram a comunicação pessoal e a colaborativa, presencial e online, impactando as instituições de ensino (MORAN, 2015).

\section{4 - Métricas de Resultados}

Tornar-se popular no YouTube é essencial para serviços de marketing e produtos (CHATZOPOULOU, 2010). O sucesso é baseado, muitas vezes, na popularidade dos vídeos através da visibilidade conquistada. Contudo, definir "popularidade" não é tão 
simples como se pode pensar, pois aspectos diferentes são capturados através das métricas de popularidade, desenvolvidas pela ferramenta para entender relacionamento e padrões temporais. O parâmetro fundamental para medir popularidade é a quantidade de vezes a que o vídeo foi assistido, mas existem outras métricas como número de comentários nos vídeos listados, número de seguidores do canal, número de avaliações e classificação média do conteúdo pelos usuários.

Segundo Holzbach (2010), ao analisar as métricas geradas pelo YouTube para medição da popularidade dos vídeos, constatou-se que, ao comunicarem à audiência sobre o que é contabilizado como popular, as métricas têm papel ativo na criação da realidade de utilização, não sendo meramente descritivas, mas também performáticas. Quanto mais popular é o vídeo, mais ele ganha escala de audiência e desperta o interesse de novos espectadores.

\section{Metodologia}

O método de pesquisa foi o de estudo de caso, com o propósito de sintetizar e analisar as informações referentes à utilização de uma ferramenta de tecnologia da informação para auxílio a universitários, caracterizando-se como um estudo descritivo através de métricas disponíveis em um player específico de vídeos online, oYouTube. Segundo Meirinhos et al. (2010), o estudo de caso é frequentemente utilizado, pois permite estudar o objeto no seu contexto real, baseado em múltiplas fontes de evidência e enquadrado em uma lógica de construção do conhecimento.

O período estudado corresponde a um comparativo entre os anos 2016 e 2017, com abordagem do estudo quantitativa, utilizando técnicas de coleta de dados através de sistema informatizado web, disponível como painel de controle do sistema.

\section{Estudo de Caso e Análise dos Resultados}

Após a revisão sobre o contexto da tecnologia na educação e as características do perfil da geração $\mathrm{Y}$, relacionada diretamente ao perfil dos atuais universitários brasileiros, foi criado pela startup objeto de estudo um modelo padrão de vídeo-aula de reforço para estes alunos. Inicialmente os conteúdos gravados foram direcionados à área de Ciências Exatas, devido ao elevado número de cursos e alunos com disciplinas em comum. Em fevereiro de 2013 foram listadas inicialmente 24 aulas no player de vídeos onlineYouTube, através do canal da empresa, com exibição gratuita para os usuários do sistema. As aulas são organizadas através de playlists (listas sequenciadas e organizadas por conteúdos) das disciplinas, que facilitam a pesquisa do conteúdo e a 
continuidade do material para estudo pelos universitários. Além disso, utilizou-se da adoção de capas personalizadas para os vídeos, com intuito de elevar a atenção do usuário.

No período de pesquisa, o canal obteve 27.477 novos usuários inscritos, ou seja, que solicitaram acompanhar o canal e serem avisados dos lançamentos de novos vídeos. As vídeo-aulas foram assistidas em 158 países diferentes, com predominância do Brasil, com $97 \%$ das visualizações, seguido por Portugal $(0,8 \%)$, Angola $(0,6 \%)$ e Moçambique $(0,5 \%)$.

Segundo as informações demográficas fornecidas pelo Analytics (ferramenta YouTube de suporte ao gestor do canal), foi constatado que $40 \%$ das pessoas que assistiram aos vídeos têm entre 18 a 24 de idade, sendo que no total das visualizações desta faixa etária $56 \%$ dos usuários são do sexo masculino e $44 \%$ é do sexo feminino, contrastando com os números totais de usuários, onde a predominância é masculina, com $63 \%$ dos espectadores. Ao somar o número de usuário de 18 a 24 anos com o número de usuários de faixa etária entre 25 e 34 anos, o resultado total é de $78 \%$.

Figura 1 - Visualizações dos Vídeos por faixa etária e sexo

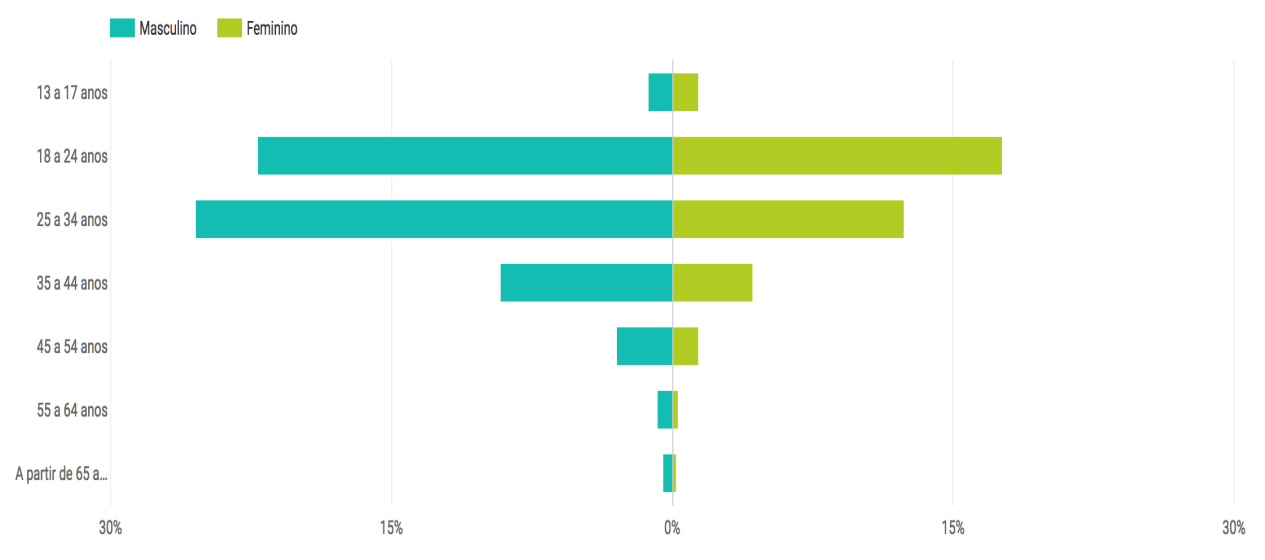

Fonte: Analytics YouTube (2018)

\section{1 - Métricas de Utilizações}

O resultado efetivo da aplicação do modelo pode ser parametrizado através de métricas oferecidas pela ferramenta Analytics, do YouTube, para o canal estudado. O número de visualizações no período estudado foi de 3.213.685. O gráfico gerado pelo Analytics mostra que, em determinados intervalos de tempo, o número de visualizações cresce de forma acentuada. Estes picos são relacionados aos períodos regulares de provas, onde 
os universitários buscam o YouTube como ferramenta complementar para seus estudos. Ao utilizar a mesma linha de raciocínio, verifica-se o número baixo de visualizações nos períodos de férias regulares. O dia 26 de novembro de 2017 registrou 14.710 visualizações, o maior número no período. Em relação aos minutos assistidos, o Analytics registou, no período estudado, 9.011 .325 minutos. Este valor corresponde a 150.188 horas ou 6.257 dias se colocados seguidamente.

Figura 2 - Acompanhamento das visualizações dos vídeos durante o período 01/01/2016 a 31/12/2017

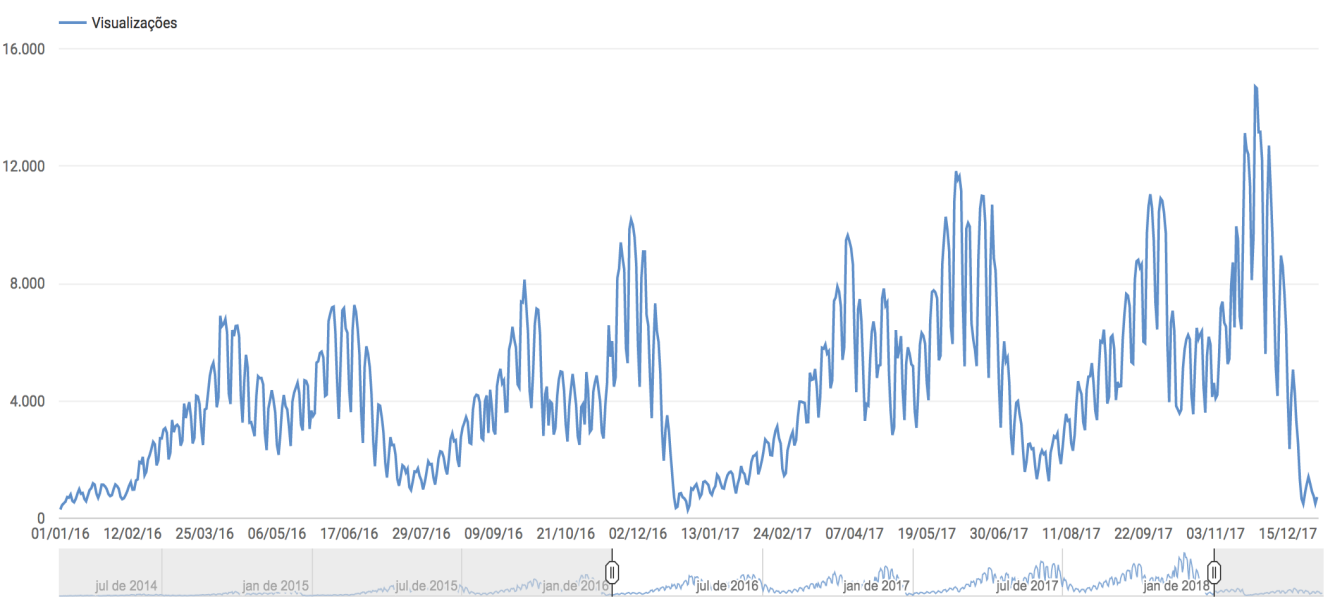

Fonte: Analytics YouTube (2018)

\section{2 - Métricas de Comportamento}

As métricas de comportamento refletem as ações dos usuários a partir das métricas de utilização. Basicamente, essas métricas auxiliam a divulgação e atestam o conteúdo em base de percepções dos vídeos assistidos no canal. Uma das formas de mensurar a aprovação através de vídeos no YouTube é a partir da ação "Gostei", onde os usuários que estiverem ativos em suas contas no podem realizar marcações nos vídeos com um "Gostei" ou contrariamente, com o botão "Não Gostei". Para este indicador, o Analytics registrou 37.903 ações de Gostei e 1.568 ações Não Gostei.

Figura 3 - Acompanhamento das métricas Gostei x Não Gostei 


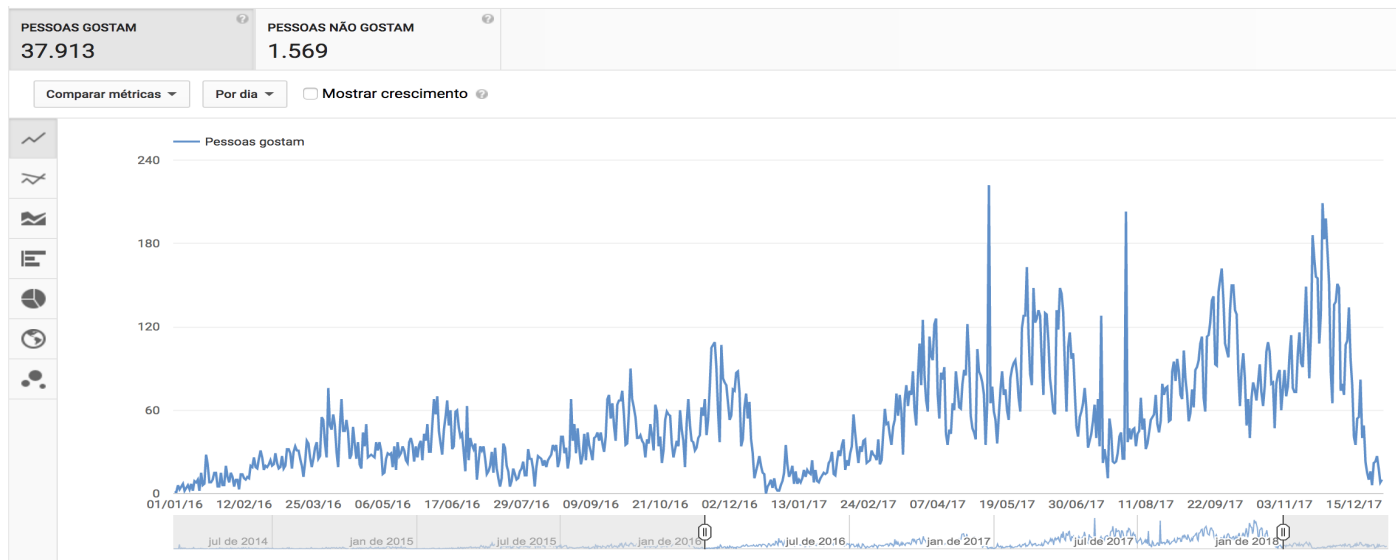

Fonte: Analytics YouTube (2018)

\section{3 - Análise dos resultados}

Para prover uma melhor comparação de resultados, foi realizada análise no crescimento baseado semestralmente no período compreendido entre 01 de janeiro de 2016 e 31 de dezembro de 2017. No período avaliado, o crescimento semestral cresceu $17 \%$ do primeiro para o segundo semestre de 2016, 22\% do segundo semestre de 2016 para o primeiro de 2017 e 16\% do primeiro semestre de 2017 para o segundo semestre de 2017.

Figura 4 - Crescimento de Visualizações por semestre

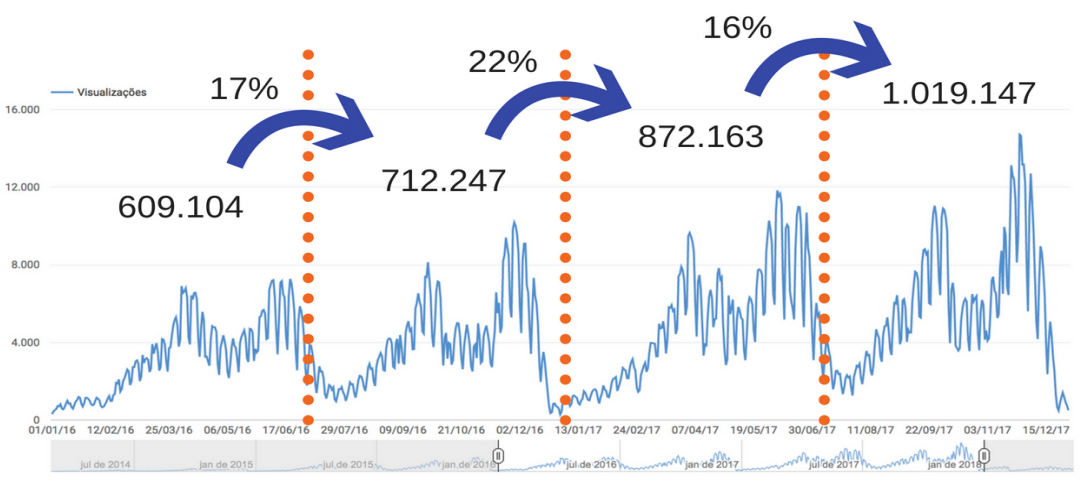

Fonte: autor (2018)

O crescimento acumulado no período total, relacionando o segundo semestre de 2017 e o primeiro semestre de 2016 foi de $67 \%$.

5 - Conclusão 
Este estudo foi realizado para tentar realizar, na prática, uma análise sobre perguntas importantes na relação entre ensino superior e tecnologias de informação através de ferramentas de apoio. A procura por novas ferramentas foi evidenciada pelas métricas de utilizações, baseadas no número de usuários inscritos no canal (acima de 35.000 inscritos) e o número de visualizações praticadas no período, que ultrapassou 3 milhões de visualizações únicas. Além disso, o estudo mostra um crescimento de mais de dois dígitos percentuais, período a período, evidenciando a utilização da ferramenta e a procura dos alunos pelo modelo em questão.

Outra conclusão importante foi sobre o perfil do aluno que utilizou o canal para estudos complementares. Mais de $70 \%$ dos usuários do canal estão compreendidos entre $18 \mathrm{e}$ 34 anos, evidenciando a geração $Y$ como público consumidor de tecnologia aliado à educação.Também foi possível concluir, através das métricas de comportamento, que as ferramentas se propagam através da internet, utilizando-se de compartilhamentos em redes sociais e em classificações com relação à qualidade e conteúdo, como as ações "Gostei". O resultado foi o crescimento constante através das análises dos ciclos de avaliações, mostrando o crescimento progressivo do canal "Me Passa Aí".

Referências Bibliográficas

ALVES, L. Educação a Distância: conceitos e história no Brasil e no mundo. Revista Brasileira de Aprendizagem Aberta e a Distância, v. 10, 2011.

CORDEIRO, Helena Talita Dante. Perfis de carreira da geração Y. 2012. Tese de Doutorado. Universidade de São Paulo.

DA EDUCAÇÃO SUPERIOR, INEP Censo. resumo técnico. Brasília: Instituto Nacional de Estudos e Pesquisas Educacionais Anísio Teixeira, 2014.

DINIZ, Cládice Nóbile; OLIVEIRA, Gilda Olinto de. O uso da tecnologia da informação entre universitários. 2013.

GIBSON, Lindsey A.; SODEMAN, William A. Millennials and Technology: Addressing the Communication Gap in Education and Practice.Organization. Development Journal, v. 32, n. 4, 2014.

HERINGER, Rosana; SOCIÓLOGA, Professora Adjunta. Expansão do ensino superior no Brasil: acesso, diferenciação interna e políticas de inclusão. In: XV Congresso Brasileiro de Sociologia. 2011. 
KENSKI, Vani Moreira. Tecnologias e ensino presencial e a distância. Papirus Editora, 2003.

MAINARDI, Andreia; MULLER, Liziany; PEREIRA, Aline Arruda. 0 cenário educacional: $O$ professor e a Tecnologia da Informação e Comunicação diante das mudanças atuais. Revista Eletrônica em Gestão, Educação e Tecnologia Ambiental, v. 18, n. 1, p. 531-544, 2014.

MAGALHÃES, Mauro de Oliveira. Sucesso e fracasso na integração do estudante à universidade: um estudo comparativo. Revista Brasileira de Orientação Profissional, v. 14, n. 2, p. 215-226, 2013.

MEIRINHOS, Manuel; OSÓRIO, António. O estudo de caso como estratégia de investigação em educação. EduSer-Revista de educação, v. 2, n. 2, 2011.

MORAN, J. M. (2015). Mudando a educação com metodologias ativas. Coleção Mídias Contemporâneas-Convergências Midiáticas, Educação e Cidadania: aproximações jovens, 2.

SCHNEIDER, Catiúcia Klug; CAETANO, Lélia; RIBEIRO, Luis Otoni Meireles. Análise de vídeos educacionais no youtube: caracteres e legibilidade. RENOTE, v. 10, n. 1, 2012.

SMITH, Patrick. Perceptions of Education as an Avenue to Life Course Success: Study of Millennials. 2014. Tese de Doutorado. University of Central Florida Orlando, Florida.

SOBROSA, Gênesis Marimar Rodrigues et al. Perspectivas de futuro profissional para jovens provenientes de classes socioeconômicas desfavorecidas. Temas em Psicologia, v. 22, n. 1, p. 223-234, 2014.

VASCONCELOS, Kátia C. et al. A Geração Y e suas âncoras de carreira.GESTÃo. Org-Revista Eletrônica de Gestão Organizacional, v. 8, n. 2, 2010.

VIEIRA, M. F. (2015). Gestão da EaD no contexto dos polos de apoio presencial da Universidade Aberta do Brasil. In: Anais $21^{\circ}$ Congresso Internacional ABED Educação a Distância, Bento Gonçalves/RS. 